\title{
TEMORES, AUSÊNCIAS E REDEFINIÇÕES: IDIOSSINCRASIAS DA IMIGRAÇÃO SENEGALESA NO SUL DO BRASIL.
}

\author{
FEARS, ABSENCES AND REDEFINITIONS: IDIOSYNCRASIES OF SE- \\ NEGALESE IMMIGRATION IN SOUTHERN OF THE BRAZIL. \\ PEURS, ABSENCES ET LES REDÉFINITIONS: PARTICULARITÉS DE \\ L'IMMIGRATION SÉNÉGALAISE AU SUD DU BRÉSIL.
}

MIEDOS, AUSENCIAS Y REDEFINICIONES: PARTICULARIDADES DE LA INMIGRACIÓN SENEGALESA EN SUR DE BRASIL.

\section{João Carlos Tedesco*}

RESUMO: O artigo analisa aspectos da imigração senegalesa no centro-norte do Rio Grande do Sul; discute o fato de ser uma imigração recente e, por isso, produz envolvimentos no campo social; centraliza as representações, as reações, os comentários e as posições dos autóctones. Por meio de questionários e narrativas orais, o texto busca descrever os complexos, custosos e perigosos caminhos para chegar ao Brasil a partir do Equador, bem como inserir-se e integrar-se na sociedade regional. Conclui que a família, o trabalho e a crença religiosa formam um tripé que alimenta, justifica e permite enfrentar as adversidades que a realidade de imigrante apresenta. Enfatiza que imigrantes e representantes associativos temem possíveis mudanças culturais que o processo integrativo na sociedade de destino vem produzindo, principalmente em torno do que expressam ser o "abrasileirar-se". Enfim, o artigo conclui que imigrantes senegaleses organizam estratégias e rituais, em seu cotidiano, para enfrentar os temores da perda de referenciais culturais e de solidariedade que os caracterizou nos primeiros anos na sociedade de destino.

Palavras-chave: Imigração senegalesa; trabalho; religião; mudanças culturais; integração social.

\footnotetext{
* Doutor em Ciências Sociais; Professor titular na Universidade de Passo Fundo (UPF), Passo Fundo, RS, Brasil; E-mail: jctedesco@upf.br
} 
ABSTRACT: The article analyzes the senegalese immigration in the central-north of Rio Grande do Sul; discussing the fact that it is a recent immigration and, accordingly, that, produces involvement in the social field; centralizes the representations, reactions, comments and positions of the autochthonous. Through questionnaires and oral narratives, the article pretend to describe the complex, costly, and dangerous ways to reach Brazil per Ecuador, as well as to integrate and insert yourself into the regional society. It is concluded that family, work and religious belief form a tripod that feeds, justifies and allows to face the adversities that the reality of immigrant presents. It emphasizes that immigrants and representative societies fear possible cultural changes that the integrative process in the destination society has been producing, mainly around what they say been "abrasileirar-se"(become brazilian). Finally, the article concludes that Senegalese immigrants organize strategies and rituals, in their daily lives, to face the fears of the lost the cultural references and solidarity that characterized them in the first few years in the destination society.

Keywords: senegalese immigration; work; religion; acculturation; social integration.

$\boldsymbol{R} \mathbf{E} \boldsymbol{S U M E}:$ L'article analyse les aspects de l'immigration sénégalaise dans le centre-nord du Rio Grande do Sul; il discute le fait du être une immigration récente et, par conséquence, elle produit des implications dans le champ social; centralise les représentations, les réactions, les commentaires et les positions des autochtones. $\dot{A}$ travers de questionnaires et de récits oraux, le texte vise à décrire les chemins complexes, coûteuses et dangereuses pour arriver au Brésil passant par l'Equateur, ainsi que l'insertion et l'intégration dans la société régional. L'article conclut que la famille, le travail et le croyance religieuse forment un trépied qui se nourrit, justifie et permet de faire face à l'adversité qui la réalité de l'immigration présente. Il souligne que les immigrants et les représentants associatifs ont peur des les possibles changements culturels qui produit le processus d'intégration dans la société de destin, surtout autour qu'ils expriment être le devenir "brésilien". De toute façon, l'article conclut que les immigrés sénégalais organise des stratégies et des rituels, dans sa vie quotidienne, pour faire face à la peur de la perte de références culturelles et de solidarité qui ont caractérisé les premières années dans la société de destin.

Mots clés: immigration sénégalaise; travail; religion; changements culturels,;intégration sociale.

RESUMEN: El artículo analisa los aspectos de la inmigración senegalesa en el centro-norte de Rio Grande do Sul; discute el 
hecho de ser una inmigración reciente, y, por eso, produce participación en el campo social; centraliza las representaciones, las reacciones, los comentários y las posiciones de los autoctonos. Por medio de cuestionarios y narrativas orales, el texto busca describir los complejos, costosos y peligrosos caminos para llegar a Brasil desde Ecuador, así como insertarse e integrarse en la sociedad regional. Concluye que la familia, el trabajo y la creencia religiosa forman un trípode que alimenta, justifica y permite enfrentar las adversidads que la realidad de inmigrante presenta. Enfatiza que inmigrantes y representantes asociativos temen posibles cambios culturales que el proceso integrativo en la sociedad de destino viene produciendo, principalmente en torno a lo que expresan ser el "abrasileirar-se". En fin, el artículo concluye que inmigrantes senegaleses organizan estrategias y rituales, en su cotidiano, para enfrentar los temores de la pérdida de referencias culturales y de solidaridad que los caracterizó en los primeros años en la sociedad de destino.

Palavras-clave: inmigración senegalesa; trabajo; religión; cambios culturales; integración social.

\section{INTRODUÇÃO}

O fenômeno migratório tornou-se um fato social amplo, totalizante no mundo atual (Seyferth et al., 2007), de experiências humanas, de mudanças sociais (aspirações, emancipações, fugas etc.) que refletem múltiplas relações, expressões (Wihtol de Wenden, 2013; Sassen, 2008). Para entender os processos que determinam as direções de seus destinos, faz-se necessário também compreender os elementos históricos e conjunturais que produzem as saídas. Nesse sentido, o caso específico do Senegal é paradigmático, pois é um país considerado democrático; não apresenta conflitos bélicos nessas últimas décadas de grande expressão emigratória, realidade essa que dificulta a obtenção do visto que identifica os imigrantes como refugiados em seus países de destino.

O Senegal é um país da África Ocidental (extremo oeste) e subsaariana; possui um território equivalente ao do estado do Rio Grande do Sul, com população, em 2016, em torno de 14 milhões, sendo a feminina superior $(50,90 \%)$ em relação à masculina $(49,10 \%)$ (CEPED, 2017). A religião islâmica é majoritária, tendo as confrarias Muride e Tijane como as de maior quantidade de adeptos. A Muride 
é a maior do país e possui correlação com a dinâmica migratória. A nação conquistou sua independência em relação à França em 1960. É composto por uma população que, nas últimas três décadas, emigra muito, aproximadamente quatro milhões de pessoas estavam fora do país em 2015, desses, 70\% estavam na Europa, com maiores presenças na França, Itália e Espanha (Malomano; Fonseca; Badi, 2015).

A imigração senegalesa para a América do Sul, em particular para o centro-sul do Brasil, vem chamando a atenção de pesquisadores, principalmente nos âmbitos econômico-laborais, sociais, culturais e religiosos. É uma imigração que expressa nova tendência dos fluxos mundiais na direção Sul-Sul, ou seja, de países empobrecidos para os considerados em vias de desenvolvimento.

Em 2015, havia registro de em torno de 41.000 imigrantes africanos no Brasil, desses, aproximadamente $30 \%$ eram senegaleses; no Rio Grande do Sul, no mesmo período havia em torno de 2.500 africanos, desses, em torno de 50\% eram senegaleses (Uebel, 2016). Os dados mais recentes de agências governamentais informam um aumento desse contingente em 2016. Porém, não há dados fidedignos nesse sentido. Em Passo Fundo e seu entorno, segundo informações da Polícia Federal com sede no referido município, havia em 2016, em torno de 1.000 senegaleses. Porém, ressalva-se que não há uma agência que possua dados atualizados, os imigrantes migram muito em razão da busca de otimização laboral, ${ }^{1}$ inclusive entre estados no interior do Brasil e entre países, em particular, do Mercosul, com maior intensidade para a Argentina.

Nesse cenário das emigrações laborais, as quais caracterizam a grande emigração senegalesa, as causalidades podem ser múltiplas e correlacionais, tendo processos estruturais e subjetivos, ambos de difícil determinação e hierarquia (Heredia; Tedesco, 2015). A fraca economia, as secas sequentes, o meio ambiente, políticas de tendências produtivistas no meio rural, as redefinições sociais de unidades familiares, o êxodo rural e a consequente concentração populacional na capital Dakar, os acordos de livre comércio com países vizinhos

1 Numa pesquisa que fizemos em janeiro de 2017 em seis frigoríficos de Passo Fundo e seu entorno (Tapejara, Marau, Serafina Corrêa e Estação), havia 367 senegaleses atuando no setor; num frigorífico apenas, havia 168. Nosso interesse no momento era analisar a questão das atividades de abate halal, somente nesse setor, nos seis frigoríficos, havia mais de 100 senegaleses. 
e da França com vários países francofones, em particular, da África Ocidental, a globalização das comunicações e informações, os horizontes religiosos, todos, em seu conjunto, produzem realidades migratórias, dentre uma série de outros elementos de ordem sóciocultural, expressos nas questões afetivas, de gênero e de poder social (Wihtol de Wenden, 2005; Fall, 2010; Ndiaye, 2016; Barau, 2007).

Esses processos todos, em tempos variados, produziram uma “cultura emigratória no país" (Fall, 2010). As primeiras emigrações pós-independência davam-se entre países vizinhos (zona da África Ocidental - Costa do Marfim, Mali, Mauritânia, Cabo Verde, Nigéria) e na dimensão sazonal. Nas décadas de 1970 e 80, a representação de que a riqueza deveria ser buscada na Europa (em especial, França, Espanha, Itália e Inglaterra) produziu grandes levas de imigrantes; após final da década de 1990, com as restrições da França e outros países da Europa, os canais da América do Norte apresentaram-se como alternativa. Em 1999, havia em torno de 400 mil senegaleses emigrados; em 2016, como já vimos, calcula-se em torno de 4 milhões. A partir do início do século XXI, outros destinos foram se constituindo, dentre eles, o Brasil (Ndione, 2016). Em 2015, as remessas financeiras dos imigrantes atingiram 17\% do PIB do país (em torno de U\$ 2 bilhões); segundo analistas, a imigração é um grande recurso econômico, porém, tem provocado uma grande dependência do país em relação ao dinheiro enviado pelos imigrantes. Havia cidades em algumas regiões do país, em 2010 e 2011, que, em torno de $80 \%$ da população, dependia desse dinheiro externo (Fall, 2010).

A emigração é vista como uma estratégia, uma ação racionalizada em termos econômico-sociais, familiares e religiosos; ela orienta práticas, aspirações familiares de mobilidade e status social (Sakho; Diop; Awissi-Sall, 2011). Em geral, até bem pouco tempo, eram os homens que emigravam, porém, as mulheres já o estão fazendo em grande dinamismo. A migração e a emigração de mulheres senegalesas intensificaram-se na década de 1990 e têm provocado profundas transformações na família, nas relações de gênero, pois as mulheres eram apreciadas no contexto da vida familiar. Ao emigrarem, elas passaram a contribuir de uma forma mais intensa na 
economia familiar. Estudos indicam que nas maiores cidades, dentre elas, Dakar, a proporção que era de 7 homens para 3 mulheres em 1990, passou de 3 homens para 2 mulheres em 2014 (CEPED, 2017). Busca-se, pela emigração, promover status social ao grupo familiar e, desse, para o sujeito que a viabiliza. "A migração é, muitas vezes, interpretada, à imagem da circuncisão, como um rito de passagem, um marco importante no curriculum individual. Seria preciso partir para ser homem, ter um status social ou reconhecimento" (Fall, 2010, p. 2). Estudos recentes informam que há uma "fuga de cérebros"; ou seja, os imigrantes possuem, em grande parte, um nível elevado de estudos; 54,2 \% dos imigrantes, em 2014, possuíam ensino superior (Shako; Diop; Mboup; Diadiou, 2015).

O destino em direção ao Brasil é bastante recente; em termos mais amplos e evidentes, não completou uma década. Para muitos dos nossos entrevistados, ela aconteceu como que por acaso. O Brasil não estava no mapa dos destinos atrativos para os senegaleses. Nas entrevistas que efetuamos, as explicações sobre as informações e a decisão e emigração para o Brasil sempre estavam correlacionadas à "existência de trabalho", "ser grande", "estar crescendo muito". O Sul do Brasil mostrava ser uma "região que é bem desenvolvida", de terem visto na internet que "aqui tinha trabalho", de terem aprendido espanhol e/ ou português devido à emigração anterior para Cabo Verde e Guiné Bissau, ou, também, Espanha, e achavam que daí seria mais fácil encontrar trabalho no Brasil, do conhecimento de que "cinco anos atrás aqui tinha muito pedido de trabalho nos frigoríficos". ${ }^{2}$ São respostas que giram em torno da noção de um país grande, de estar, no período, crescendo economicamente e, portanto, de ter trabalho, de legislação que favoreceria a demanda por refúgio (essa como estratégia para inserção no país e, como consequência, no mercado de trabalho).

Entretanto, o que nos chamou mais a atenção nas respostas foi o fato dos entrevistados enfatizarem que, no Senegal, particularmente na capital, Dakar, pós-anos 2000, foram desenvolvidas algumas campanhas publicitárias sobre o Brasil por agências de viagens como "país grande", de "muito trabalho e sem guerra", "era fácil vir pra cá", "tudo

2 Entrevistas diretas com senegaleses em suas residências na cidade de Passo Fundo; algumas delas na forma coletiva aos domingos à noite. 
aqui é tranquilo e que dava para mandar muito dinheiro para casa". A "popularidade e a visita do Lula [presidente do Brasil entre 20022010] nos países vizinhos do Senegal e a sua proposta de acolhida aos africanos no país também ajudou". Portanto, as causalidades foram múltiplas, revelavam-se em horizontes subjetivos, redes que foram se constituindo, dinâmicas políticas e econômicas que demonstravam serem favoráveis, legislações mais brandas, se comparadas às de espaços de maior expressão migratória, possibilidades de deslocamentos intercontinentais, horizontes religiosos (confrarias) que intencionavam se transnacionalizar, famílias que decidiram deslocar membros para permitir a permanência de outros no espaço de origem, etc.

Tendo presente essa nova trajetória migratória de senegaleses, das aventuras e desconhecimentos, das múltiplas causalidades, dos desencantos em correspondência com as "propagandas do Brasil no Senegal", abordaremos algumas dinâmicas que, de uma realidade imberbe, foram apreendidas pelos contatos de campo, por narrativas diretas de imigrantes. O objetivo é perceber tensões, redefinições, estratégias frente aos limites e às ausências, alguns processos integrativos e que conduzem, como nos disse um representante religioso dos senegaleses, preocupado com o "abrasileiramento" e que, talvez, não muito diferente de outros grupos e em outros espaços migratórios, revelam alguns dos dinamismos que, na atualidade, o fenômeno migratório internacional no Brasil produz.

Em termos de apreensão de dados, buscamos contatos com imigrantes nos locais de trabalho e em algumas de suas residências em Passo Fundo, Marau e Tapejara, ambos no Norte do Rio Grande do Sul. Entrevistamos empregadores e responsáveis de determinados setores em que há senegaleses no quadro de trabalhadores. $\mathrm{O}$ teor central das entrevistas girava em torno das relações de trabalho, das aprendizagens e experiências prévias, do convívio social no espaço de trabalho, opções, perspectivas e performances. Buscamos correlacionar a dimensão do trabalho com família e essa com a esfera religiosa. A intenção era perceber como esses horizontes dinamizam a realidade de imigrante. Entrevistamos 23 senegaleses 
e seis empregadores. ${ }^{3}$ Fizemos algumas entrevistas aprofundadas sobre fragmentos da história de vida de imigrantes, ou seja, alguns elementos da situação de suas famílias, a informação sobre o Brasil antes de emigrar, a decisão, os processos do translado, a inserção no país de destino, a busca por trabalho, moradia e os processos de integração com co-nacionais e autóctones.

Marcamos presença nas festas de confrarias religiosas em Passo Fundo há vários anos, nas quais percebemos a importância dos rituais coletivos, das associações e vínculos religiosos na vida do imigrante. Promovemos algumas entrevistas com lideranças religiosas e participamos de vários encontros na mesquita de Passo Fundo nas sextas-feiras a tarde e nos domingos. ${ }^{4}$ Participamos de jogos de futebol com senegaleses, ou os convidamos para jogar conosco. Enfim, buscamos formas de contatos, algumas mais estruturadas, outras mais informais para obter informações, dialogar e produzir conhecimentos em torno do tema.

Estruturamos nosso artigo analisando primeiramente alguns dos complexos processos que conduzem os imigrantes senegaleses até o extremo norte do país. A intenção é perceber os difíceis caminhos, seus enfrentamentos e a força que os faz atingir os objetivos. Posteriormente, abordamos alguns aspectos do horizonte sócio-cultural, ou seja, o campo das ausências e recomposições, tentando entender como imigrantes, nos limites de seu cotidiano, conseguem reconfigurar elementos de sua tradição, crenças e papéis sociais e de gênero. Por fim, são analisados alguns aspectos que correlacionam o mundo religioso

3 Não houve nenhum critério para definir ou selecionar os interlocutores (por exemplo, idade, sexo, escolarização, local de proveniência no país, etc.). Buscamos otimizar as possibilidades que obtivemos para contatar com eles, muitos dos quais, através da denominada "bola de neve" (em que um vai indicando outros). Houve muitas dificuldades em razão de que muitos trabalham em turnos noturnos e dormem durante o dia, outros, estão na espera de obter um novo visto de permanência no país e, por isso, esboçava reação negativa em participar das nossas entrevistas, dentre uma série de outras questões. Estamos organizando um outro livro sobre o tema, no qual, detalharemos esses processos e as implicações de pesquisar com imigrantes, principalmente num cenário de grandes limites como o vivido atualmente por eles.

4 Tivemos oportunidade de viajar ao Senegal no mês de abril e maio de 2017 para um estágio de pesquisa de campo e de intercâmbio com professores da Universidade de Dakar (Cheik Anta Diop) sobre o tema da imigração de senegaleses em várias partes do mundo, principalmente, para a América Latina. Essa experiência foi fundamental para compreendermos alguns processos que ocasionaram e continuam propiciando as saídas de imigrantes, em particular, para a América do Sul. Viajamos também no mês de janeiro de 2016 para as cidades de Brasiléia e Assis Brasil no estado do Acre. Nesses cenários conseguimos entender algum dos processos que viabilizam a chegada de vários grupos étnicos até o Brasil, em particular, senegaleses, bem como sua dispersão para várias cidades do país, com preponderância para São Paulo. 
e o trabalho, alguns dos processos integrativos e a ambiguidade identitária que vai se constituindo frente à forte e temerosa tendência do "abrasileirar-se", como alguns entrevistados nos disseram.

\section{"Cheguei..., seja aqui o que Deus desejar": caminhos e descamin- hos para chegar ao Brasil}

Ainda que se esteja vivendo num cenário de um mundo globalizado, de fronteiras deslizantes (Bauman, 1999), mas, para muitos imigrantes, essa realidade não se evidencia. Dificilmente senegaleses conseguem vistos para viajar ao Brasil para trabalho. Para turismo, as exigências e os custos são muito altos, fato esse que inviabiliza a tentativa de emigrar. Fragmentos de entrevistas aprofundadas que fizemos revelam isso.

"Se tu vais na Embaixada Brasileira em Dakar, eles não te dão o visto; tu podes dizer que vai pro Brasil comprar roupa ou outra coisa, eles querem saber a reserva do hotel, quanto dinheiro tu tens e mais um monte de coisas; então fica difícil; se tu dizes que vais trabalhar, eles não te dão nada". 5

Não obstante, os desembolsos financeiros são muito altos mesmo optando por caminhos alternativos, ou seja, até 2016 era possível conseguir vistos para viajar do Senegal ao Equador e, desse país, atingir, por terra, a fronteira norte do Brasil. "[...], eu gastei mais ou menos 16 mil reais. Meus pais venderam coisas para que eu pudesse vir. Tu paga a metade quando sai e, a outra metade os pais pagam quando tu avisas que chegou no Brasil; é assim que funciona [...]. Agora o governo do Equador dificultou também, acho que foi pressão do Brasil". ${ }^{6}$

Desse modo, no horizonte das estratégias, imigrantes encontram canais alternativos, porém, difíceis e perigosos. Muitos imigrantes senegaleses situados em Passo Fundo experimentaram uma longa jornada para conseguir alcançar as terras brasileiras. Para muitos que tentam aportar na Europa, as embarcações marítimas precárias são a alternativa, porém, a probabilidades de serem

5 Entrevista direta com senegalês (n. 17); o interlocutor está no Brasil, há quatro anos; emigrou sozinho; reside atualmente em Passo Fundo e trabalha na construção civil.

6 Idem. 
interceptadas pelas guardas costeiras dos países de destino é muito grande, além do alto risco de vida. ${ }^{7}$ Para os que buscaram chegar ao Brasil, cruzar fronteiras de países latino-americanos passou a ser lugar comum. A partir de algumas entrevistas, conseguimos abordar questões relacionadas à história do tenso trajeto até chegar ao Brasil:

"No Senegal, eu fui tentar o visto para vir, mas não deu certo, então, segui outros que conseguiram visto com gente que faz isso, como eu falei. [...]. Eu gastei pra estar aqui nessa casa no primeiro dia, mais de 13 mil reais, tudo isso, porque depois que tu começas não tem mais volta; ou tu perdes tudo para depois recuperar, ou tu ficas sem nada; eles [intermediadores] vão te tirar o dinheiro de todo o jeito. [...]. Eu levei 19 dias para chegar aqui onde estou agora, nessa casa; isso que vim direto do Acre [Brasiléia] para cá. [...]. Nós éramos em seis, um queria desistir e vimos ele ser assaltado e abandonado no meio de um mato, de noite, no Equador; até hoje ninguém sabe mais dele, devem ter matado ele. [...]; sentimos muito medo e, por isso, resolvemos ir até o fim. [...]. Atravessamos vários países, de ônibus, de carro, a pé, tudo depois de Guayaquil. Ninguém sabia onde estava, apenas te diziam que era assim mesmo e que iríamos entrar no Brasil, pelo Acre e que o caminho final era lá [...]". ${ }^{8}$

Permanecer mais de 20 dias tentando atravessar países como Equador, Peru e Bolívia foi expresso como lugar comum nas narrativas de entrevistados. Pagar propinas a militares de fronteiras, ficar retido por dias até decidir desembolsar dinheiro, sob constante ameaça de retornar e perder tudo o que desembolsou, "pessoas estranhas que se apresentavam para auxiliar no translado; tinha haitiano e outros africanos também", etc., foi relatado também.

"Em cada lugar, cada país, era gente diferente, ninguém entendia a

7 As mortes nas costas marítimas da Itália e da Espanha (nessa, em Celta), tornaram-se constantes nos últimos anos. Em 2016, registraram-se mais de 4 mil mortes de imigrantes somente no Mediterrâneo (Bauman, 2017).

8 Entrevista direta com senegalês (n. 11); o interlocutor está no Brasil há dois anos e meio; emigrou com alguns conterrâneos de Casamance, Sul do país; reside em Passo Fundo e trabalha no setor de abate halal de um frigorífico.

9 Idem. 
língua; em algum lugar tinha africano junto, de outros países também que estavam com os caras [intermediadores]. [...]. Foi muito sofrido. Eu acho que cheguei até aqui porque não estava sozinho, senão teria desistido, ou não sei o que teria acontecido comigo". ${ }^{10}$

Imigrantes relatam que o custo é muito alto e, por isso, apostavam muito na chegada do destino e que não tinham a menor ideia de que a realidade que se apresentou seria aquela. $\mathrm{O}$ desencanto foi muito grande.

"Eu nunca imaginei que seria tão difícil chegar até aqui. Por isso que te falo que não quero que minha esposa e nem quem me pede para vir para o Brasil, passe o que passei. Nunca mais. [...]. Preciso muito mais de um ano trabalhando para pagar o que me custou para vir até aqui; eu e outros também vendemos muita coisa lá para ter esse dinheiro". ${ }^{11}$ Narrações sintetizadas a seguir revelam os tortuosos caminhos e as dificuldades enfrentadas também por outros imigrantes, em particular, haitianos e ganeses. Um deles, inclusive, relatou que, devido ao vírus do ebola na África, ficou cinco dias retido na fronteira de Puerto Maldonado porque "as autoridades brasileiras não queriam que entrássemos no Brasil sem a comprovação da vacina, alguns até tentavam mentir que eram haitianos". Promessas, pressões, barreiras, temores, mediações, desconhecimentos, dentre outros processos faziam parte desse longo caminho até chegar ao Brasil.

"Se eu te contar tudo vai mais de um dia, pois fiquei mais de uma semana sem saber bem onde eu estava, se iria conseguir ir para frente, se tinha de voltar. Eles [coiotes] diziam sempre que tinha de ter paciência e que eu não estaria jogando fora o dinheiro, que era que nem na fronteira do México com os EUA: é difícil, mas depois compensa e que o Brasil era grande, que não tinha problema nenhum, era só esperar o momento certo para atravessar a fronteira. [...]. Tinha africano junto com eles todos, haitianos [...]. A noite era pior, porque tu não sabias se dava ou não para atravessar onde eles te

10 Entrevista direta com senegalês (n. 5); o interlocutor está no Brasil há quase cinco anos; emigrou sozinho, residia na cidade de Dakar; habita em Passo Fundo e trabalha num supermercado.

11 Entrevista direta com senegalês (n. 13); o interlocutor está no Brasil há dois anos; emigrou de Dakar junto com quatro co-nacionais; reside atualmente em Passo Fundo e trabalha em frigorífico. 
mandavam; tu pegavas um ônibus e ia para um lugar, depois, se não dava certo, voltava e, ninguém te dava explicação, só te mandavam confiar e ficar quieto; não dava para registrar nada do celular; um haitiano apanhou muito porque tentou, escondido, tirar foto, apanhou na frente da mulher. [...]. Na fronteira com o Brasil queriam fazer exame para ver se tínhamos o vírus do ebola, que diziam que era o africano que trouxe para cá. [...]. É triste passar por tudo isso. [...], não recomendo para ninguém vir por onde eu vim". ${ }^{2}$

Outros entrevistados revelam que "não dava para registrar, ou porque te tiravam os celulares, ou porque te ameaçavam"; "nos orientavam em meio as matas, noite a dentro por muitas horas; fizemos acampamentos por três noites no meio das matas, ninguém sabia onde estava"; "quando você pisa no Brasil, eles te fazem ligar para os familiares pagarem a viagem"; “de um país para outro são pessoas diferentes; tem quem fala árabe, wolof, espanhol, português"; "eles te fazem esperar para dar um grupo, não muito grande porque tem de viajar de pequenos ônibus ou de carro"; "eu fiquei mais de 10 dias entre um país e outro; a gente ia e retornava, nunca entendi porque, eles só te mandam fazer tal e tal coisa"; "todo mundo fica desesperado e com muito medo".13

Depois de entrarem no país, os senegaleses precisam conseguir regularizar parcialmente sua situação, optando pelo pedido de refúgio, porém, devido aos trâmites brasileiros e à defasagem legislativa, possibilitam a regularização a partir de um visto provisório, válido enquanto o processo de análise da condição de refugiado é tramitado.

Imigrantes enfatizam que a proteção e salvaguarda religiosa, a presença de outros imigrantes na mesma situação, o desembolso efetuado, o sonho de uma vida melhor para si e, principalmente, para sua família, lhes garantia a força para enfrentar essas situações difíceis e perigosas do trajeto até chegar ao Brasil. A narrativa a seguir, ainda que longa, sintetiza os múltiplos processos vividos pelos imi-

12 Entrevista direta com senegalês (n. 3); o interlocutor está no Brasil há mais de cinco anos, porém, já reemigrou para a Argentina e Chile; retornou ao Brasil no final de 2016; emigrou sozinho do Senegal; reside atualmente em Passo Fundo e trabalha em frigorífico.

13 Entrevistas diretas realizadas junto a um grupo de senegaleses situados em Passo Fundo, em sua residência, em 14 de setembro de 2016. A maioria deles trabalhava, no período, como vendedores ambulantes em Passo Fundo e em cidades vizinhas. 
grantes desde a saída do Senegal e a chegada em Passo Fundo:

"Eu queria ir para a Itália como a maioria de meus conhecidos, mas o consulado negou. Eu recém tinha casado e já tinha uma filha de alguns meses, precisava melhorar de vida, dar condições para minha mulher e filha. [...]. Meu pai é falecido, então minha mãe fez de tudo para mim sair; minha esposa chorou, mas entendeu que eu era responsável por ela, minha filha, minha mãe e minha sogra. [...]. Um amigo de Dakar me informou sobre o Brasil e a ligação com o Equador. Fiquei mais de 15 dias pensando, conversando, vendo se era bom, porém, não tinha ninguém, nenhum conhecido. Vi que seria difícil. Depois recebi a ligação do amigo de Dakar (não quis revelar o nome), informando que a passagem custaria mais ou menos o equivalente a R\$ 2.500,00 até Guayaquil no Equador. Comprei para turismo, de um mês, sabia que se desse certo, eu perderia a passagem de volta. Arrisquei. Vendi computador, mais algumas coisas. [...]. O amigo me garantiu que tinha conhecido em Quito e até na fronteira com o Brasil, ele podia me acompanhar e me ajudar com gente conhecida dele. Paguei um bom dinheiro para ele também, quase o valor da passagem. Me cobrava em dólar e, eu pensei que a moeda no Brasil fosse dólar. Cheguei em Guayaquil, segui as orientações, peguei ônibus para Quito, lá fui para o Hotel Tropical durante uma semana. Quando vinha a informação de que poderia seguir viagem, aí peguei o ônibus para uma cidade de fronteira com o Equador (não sabia o nome). Lá, eu informei que ia visitar um amigo em Lima, com isso entrei no Peru. Em Lima, fiquei mais um bom tempo num hotel; de lá, peguei o ônibus e fui para Puerto Maldonado. Dessa cidade, com uma vã, juntos, vários imigrantes que estavam no hotel, fomos para uma cidade de fronteira com o Brasil (não lembra nome). Na fronteira com o Brasil, a polícia não queria deixar entrar, ficamos todos, quase uma semana nessa cidade, até que conseguimos um visto de 15 dias. Aí fomos para Rio Branco no Acre; nessa cidade, fomos todos solicitar refúgio na Polícia Federal. Esperamos mais de uma semana e, com o documento na mão, eu e mais alguns outros senegaleses, pagamos passagem $(R \$ 350,00)$ 
para São Paulo. Lá ficamos em casa de senegaleses mais ou menos um mês e, não havia trabalho, não sabia falar uma palavra, para vender na rua tem de saber falar. Um amigo meu tinha um amigo em Passo Fundo e convenceu ele para vir para cá e, eu vim junto, disse que aqui tinha trabalho. Já faz dois anos e meio que estou aqui. [...]. Da saída do Senegal até entrar no Brasil, acho que durou quase um mês. Foi muito difícil, muito difícil. Agora não posso retornar ao meu país, porque não consigo mais visto para voltar pra cá. Então, estou numa situação bem difícil, com trabalho, mas bem difícil; dois anos e meio sem encontrar a minha mulher e minha filha". ${ }^{14}$

Enfim, as narrativas que apresentamos são expressões de muitas outras que obtivemos sobre o difícil caminho a ser trilhado por imigrantes senegaleses que optaram por chegar ao Brasil. Já vimos que emigrar é uma aventura, é caminhar para um desconhecido, é distanciar-se da família para auxiliá-la melhor, expressa maturidade e responsabilidade do indivíduo em relação ao seu grupo familiar, manifestação de um rito para a vida adulta e que carrega esperança e muito desejo de melhorar de vida. Isso também lhes dá alimento para o enfrentamento das dificuldades, pois, como muitos entrevistados diziam, "no Senegal não tem emprego, lá não tem nada". O "sonho europeu", como um entrevistado nos disse, foi transferido para o Brasil. A idealização das comodidades materiais, de triunfar em meio aos amigos e familiares, obter dinheiro para a casa própria, ter dignidade, dentre outras coisas, sem emigrar, segundo entrevistados, torna-se quase impossível nas atuais condições do seu país. Esse intento e a pressão para dar certo condicionam os imigrantes a enfrentar caminhos difíceis, estratégias para burlar legislações restritivas, riscos de vida e, a realizá-lo, entregar-se intensivamente no horizonte laboral como forma de compensação e expressão de intencionalidade do ato migratório.

\section{"Meu samba é um pouco dos dois lugares": ausências e recomposições}

14 Entrevista direta com senegalês (n. 7); o interlocutor está no Brasil, há um pouco mais de dois anos; emigrou sozinho; reside atualmente em Passo Fundo e trabalha no comércio de frutas e verduras. O entrevistado está em processo de reagrupamento familiar; no momento da entrevista, sua esposa e filhas estavam se preparando para viajar ao Brasil. 
Imigrantes são indivíduos em ligação; sujeitos conectados, que expressam e se esforçam para continuar dinamizando lógicas de afetos; essas se manifestam em múltiplos âmbitos e cimentam relações entre os que partem, os que ficam e os que favorecem ou mediam a decisão de emigrar e as ações entre os dois primeiros. Há, nesse processo, os vínculos e ligações parentais, de vizinhança, de amizade, de identidade étnica e religiosa. Diz Mbodji (2008, p. 312) que "partir é morrer de ausências". A separação, a sua consequente fragmentação familiar, os limites das condições objetivas do viver cotidiano como imigrante, as dúvidas e incertezas que chocavam seu mundo até então constituído são expressivas de ausências. Um senegalês entrevistado ${ }^{15}$ disse que deixou "o que eu amava e também o que detestava"; enfatizou que os dois continentes produziram separações e novas junções. Essas, segundo ele, são dinâmicas e dialetizam a sua vida; comenta que "meu samba é um pouco dos dois lugares [...], perdi já muito de lá e ganhei outras aqui [...]"; ou seja, esforça-se para continuar sendo o indivíduo que era antes de emigrar, mas, sente a necessidade de "abrasileirar-se", como ele nos disse. O reterritorializar-se afetivo (família, religião, amizades, parentesco) e geográfico revela ser um movimento complexo entre lugares, pessoas e sentimentos (Simon, 2008).

O entrevistado enfatiza que seu samba é feito de muita nostalgia da família de origem e a composta por ele, sua esposa e filha. Porém, ressalva que a emigração está possibilitando melhores condições de vida econômica e financeira às duas famílias, inclusive, algumas vezes ajudando seu sogro e sogra. Ele disse que "agora entende porque todo mundo quer migrar lá, as famílias ficam melhor com alguém indo trabalhar em outro país; se ausentam de casa para deixar melhor os que ficam e eles [emigrantes) também". Os filhos imigrantes são a esperança da família. A mulher é valorizada na família pelo sucesso de seu filho; desse modo, são viabilizados os meios e vínculos para concretizar a emigração de filhos quando atin-

15 Entrevista direta (n. 4) com senegalês, da região de Casamance. Ele está no Brasil há três anos, em Passo Fundo há um ano e meio; está em situação de visto permanente até 2020, emigrou sozinho, deixou a esposa e um filho no Senegal. 
girem maioridade. "A concorrência entre coesposas leva a mãe a financiar o projeto migratório de seu filho através de suas economias" (Shako; Diop; Mboup; Diadiou, 2015, p. 42). Para isso, há um amplo conjunto de processos internos (no vilarejo, na cidade, no interior do país) e externos que são estruturados para tanto.

Essas redes informais demonstram que os imigrantes são também sujeitos ativos, capazes de produzir estratégias, adaptação em contextos diversos frente às adversidades. As redes facilitam saídas e chegadas, gestão da documentação, emprego, comunicação, trocas econômicas e sociais. Elas fazem com que os imigrantes possam manter a unidade familiar e parental ligada com a comunidade de origem (Ambrosini, 2008). Devemos considerar que os imigrantes são sujeitos que transitam em múltiplos territórios e, por isso, conectam-se e se articulam por várias redes em fronteiras também diversas (religiosas, linguísticas, culturais, geográficas e políticas. Desse modo, eles diversificam seus pertencimentos, suas relações com os espaços e com as esferas que se retroalimentam (Kaag, 2006). Entendida assim, a imigração é também circulação, ou seja, processo que se dá em interligação do aqui e do acolá (retornos, trânsitos, relações mais fortes ou não num determinado lugar) por várias estratégias em vários espaços nos lugares de destino.

Nesse sentido, no caso específico do Senegal, estudos revelam certas especificidades de destinos em correspondência com a origem dos fluxos, ou seja, os do Vale do rio Senegal dirigiram-se para a França e aos vizinhos do Senegal; os do Bassin Arachidier (região mais central), em grande crise agrícola, emigraram para o Sul da Europa (Itália, Espanha e Portugal), os da região de Dakar dirigiram-se para o Norte da Europa e para os Estados Unidos (Thiam; Crowley, 2014; Ndione, 2016). Para o Brasil e, em particular, para a região de Passo Fundo (centro-norte do Rio Grande do Sul), segundo nosso levantamento de campo, mais de $30 \%$ de nossos entrevistados informam ser da região de Casamance, sul do Senegal, 27\% da capital Dakar e seu entorno. Outros informam ser de grandes cidades ou próximas de Diourbel, Thiès, Kalaouka e Saint Louis. Em geral, eles informam cidades de maior expressão, as quais se localizam 
próximas de seus pequenos vilarejos ou municípios do entorno desses centros maiores.

\section{"A emigração vem mudando o Senegal e as pessoas também": dinâmicas familiares e modernização sociotécnica}

Já vimos que a família está no centro do processo migratório (no antes, durante, depois e nos retornos); é a que justifica e legitima o ato de partir. Porém, mudanças vão ocorrendo nesse dinamismo em movimento de pessoas em seu interior. A possibilidade de emigrar faz com que seja reduzida a prole familiar dos que ficam (Ndione, 2016), pois há fragmentação da família pela saída de um dos cônjuges, com maior preponderância do marido/pai; além de que imigrantes, nos locais de destino, quando é possível recompor famílias, as pesquisas demonstram que imigrantes fazem menos filhos do que se estivessem no espaço original (Ambrosini, 2010). Estudos sobre imigração na Europa enfatizam que essa realidade acaba indo na contracorrente do que se espera dos imigrantes. Países como a Itália, Alemanha e França contam com os imigrantes no crescimento demográfico do país, porém, isso não acontece com normalidade, pois eles têm dificuldade em gerar filhos fora de seu local de origem em razão do aumento dos custos de moradia e de sobrevivência, da redução do tempo de trabalho, em geral da mulher/mãe, da ausência de políticas sociais mais efetivas para eles, de possíveis socializações ocidentalizadas em vários campos sócio-culturais (Kaag, 2006).

"Quando retornei, fui uma vez só, e vi que muita coisa mudou em Casamance. As pessoas dizem que o Senegal mudou, que a imigração vem mudando o país, as pessoas, que é muito produto da Europa, do jeito da Europa, muita coisa da China. [...]. Quem sai deixa melhor as famílias. Eu estou guardando dinheiro agora para comprar um carro para meu irmão. [...]. Antes o pessoal enviava dinheiro para melhorar ou terminar a casa, agora é carro e roupa de grife; as pessoas querem se mostrar melhor [...]". 
Em correspondência com esses processos, redefinem-se inúmeras questões de ordem econômica, territorial e de papéis de gênero na família; mulheres assumem responsabilidades maiores na educação dos filhos, no cuidado com os idosos da família ampliada, administram os recursos financeiros advindos do exterior, envolvem-se com a educação, socialização e inserção no mundo religioso dos filhos, dentre uma série de outras questões.

A emigração passa a ser uma estratégia para permitir o equilíbrio entre a população e as possibilidades do meio em fazer face às dificuldades socioeconômicas. Ela exerce um amplo processo de mudança nas microrrelações familiares, sociais, culturais, além de ser um grande recurso econômico, demográfico e religioso (Gamberoni; Pistocchi, 2013). Mulheres, nos espaços de origem, assumem atividades que até então não eram de sua atribuição sócio-cultural; imigrantes fazem o mesmo. Narrativas de entrevistados enfatizam a intensa dependência financeira das esposas. "Ela (esposa) espera todo o dia o dinheiro daqui. [...]. Eu mando um pouco por semana, porque senão ela gasta tudo numa pegada só, troca de celular, essas coisas modernas. Pago sempre taxa (transferência de dinheiro), mas é melhor assim. Daí eu controlo tudo". ${ }^{16}$ Muitos papéis, tarefas, funções e obrigações podem mudar, porém, mesmo no espaço migratório, relações patriarcais permanecem.

Em razão dessa dependência financeira e da necessidade de redefinir esse processo, bem como outros de ordem cultural e social, senegalesas emigram; elas expressam e dinamizam o contexto de uma sociedade pós-fordista, baseada na emigração dos serviços, na flexibilização no mercado de trabalho; seu papel também é importante na esfera da reprodução fisica e simbólica da família, com suas responsabilidades e deveres (Ambrosini, 2010).

Entrevistados enfatizam que, primeiramente, o dinheiro enviado para a família é para suprir demandas de alimentação, vestuário e moradia; porém, recursos técnicos como computadores, televisores, carros, motos, celulares, dentre outros, são identificados

16 Entrevista direta com senegalês (n. 9); ele emigrou para o Brasil há três anos; nesse período, esteve por quase um ano na Argentina. Reside numa pensão em que há mais de duas dezenas de imigrantes; trabalha num frigorífico na cidade de Marau. 
como fruto dos recursos enviados. Dois imigrantes informaram que possuem contas bancárias, tanto no Senegal, quanto no Brasil. Percebe-se que se passou de uma dimensão econômica de subsistência da emigração para outra com princípio de acumulação.

Entendemos que seja necessário perceber processos estruturais e estratégias dos sujeitos/grupos sociais na questão da mobilidade geográfica. Há, sem dúvida, além dessa questão da família, uma estreita correlação entre economia e imigração. Já é lugar comum nas análises sobre imigração que os sujeitos que emigram melhoram o contexto socioeconômico do cenário de origem através dos fluxos de remessas, pela modernização social e tecnológica (consumo e atividades produtivas, acesso à educação dos filhos, etc.). Por isso, há um ativismo dos imigrantes na dimensão transnacional e o melhoramento das condições de vida no cenário familiar e comunitário de origem (Ambrosini, 2008). "O Senegal vem mudando, os pais da gente dizem isso. $O$ imigrante volta com outra cabeça; uns até retornam pra ficar com a família e ficam mais de meses lá sem trabalhar, só gastanto o dinheiro lá”. Essa dimensão do retorno é muito significativa, pois materializa no local de origem o imaginário da emigração, produz a contrapartida e a redenção frente à exclusão social no espaço de destino; revela um retorno do filho próspero e, sem dúvida, serve de atração para novas decisões de outros potenciais emigrantes.

Diz Sayad (2008) que o desejo de retornar significa um reclamo às origens, à condição inicial, àquela de emigrante antes de imigrante; é algo que está no âmago da condição de imigrante, que implica numa concepção de tempo em que o futuro é redirecionado como se fosse um retorno a si mesmo, ao seu grupo, ou seja, uma retrospectiva pessoal. Desse modo, a emigração, a identidade de migrante, de retornado e de reemigrante, revela múltiplos dinamismos, movimentos e alterações que se processam na mudança dos territórios e nas condições da vida cotidiana dos sujeitos; são realidades complexas, não definidas a priori e que operam mudanças subjetivas, valorativas e nas idealizações.

É importante ressalvar que nem todos os retornos são tão prósperos. Analistas enfatizam que a crise econômica européia e americana, bem como a latinoamericana, pós-2008, vem produzin- 
do retornos de emigrantes que não conseguiram realizar seu sonho, bem como redefinições geográficas de pouca expressão, em particular, para países do entorno do Senegal, como aconteceu na segunda metade do século XX (Fall, 2010). Com isso, emigrantes podem sair e retornar mais facilmente, inclusive, produzindo sazonalidades, ou seja, se são filhos de pequenos agricultores, nos poucos meses chuvosos do país, podem retornar para auxiliar a família nas plantações e no cultivo de foragens para animais..$^{17}$

\section{"Trabalhar mais do que rezar": limites e fragilidades na ritua- liazação religiosa}

O mundo religioso, regado de intencionalidades e expressões fomentadas em contextos em constante modificação, serve ao imigrante como uma importante bagagem cultural que pode ser apropriada de diversas maneiras no processo pelo qual o indivíduo em movimento precisa passar. $\mathrm{O}$ mundo religioso, além de transnacionalizar e ressimbolizar, torna suportável as adversidades que os imigrantes estão expostos, num quadro cultural diferente e, muitas vezes, com expressões de hostilidades, como as que podem ser observadas na realidade local e em casos internacionais (Rogoff, 2005).

A emigração e o trabalho do imigrante revestem-se de múltiplas determinações e significações. A dimensão religiosa islâmica é parte integrante da vida do senegalês; com isso, no âmbito migratório, ela se faz sentir como muito importante e fundamental. Há um grande esforço para manter as raízes e tradições religiosas (Dial; Sakho, 2014). Além da ritualidade específica, outras dimensões complementam e formam a totalidade desse universo tão significativo para quem emigra. Junto a ela está o trabalho, esse torna-se a prova de fé para o membro da confraria Muride. Ahmadu Bamba, seu histórico líder religioso, já ensinava que "para além dos mares e dos continentes levarei a mensagem a todos os filhos de Adão" (apud Friedberg, 2013).

Nos locais de pesquisa, os senegaleses entrevistados fizeram questão de correlacionar o trabalho com a dimensão religiosa, ou meintensamente evidenciadas por estudiosos da emigração senegalesa. 
lhor, o primeiro como sendo parte integrante e central da segunda. É oportuno lembrar que, para os senegaleses membros da confraria Mouride, o trabalho tem a conotação de liberdade. A vida se baseia no trabalho, é um ato de fé e de obrigação moral, ultrapassando o sentido econômico que representa (Barau, 2012). Nas orientações religiosas da confraria, há o enaltecimento do trabalho duro, do sacrifício, das privações da vida longe da família e pela família. O trabalho e o seu sacrifício tornam-se santificantes (Malomano; Fonseca; Badi, 2015).

"Eu trabalho no setor halal do frigorífico. Lá a gente trabalha uma hora e descansa outra. Daí aproveita para fazer as orações que deveriam ser feitas durante o abate do frango"; "o patrão não permite que a gente reze durante o trabalho, ele disse que é 'para fazer isso a noite e que vale a mesma coisa'. Eu discordo. Nós sempre temos as horas para orar; eu saio e vou em algum lugar, não no banheiro, e faço as orações do dia"; "aqui se reza pouco; trabalha mais do que reza, um pouco nós somos os culpados, um pouco também as pessoas daqui, os brasileiros, não valorizam esse nosso costume de rezar várias vezes ao dia". ${ }^{18}$ Entrevistamos um responsável pela associação islã da região de Passo Fundo, ele nos disse que há mudança em curso e que é difícil seguir as regras religiosas num cenário diferente, de ausências de crenças e da importância da religião. Segundo eles, imigrantes, reduzem muito o tempo da oração, muitos trabalham de dia e estudam à noite, fato esse que dificulta e os envolve em múltiplas atividades, deixando de lado rituais comuns do âmbito religioso. O referido entrevistado, em sua narrativa, dá ênfase ao fato de que há na região muitos frigoríficos que estruturam o abate de aves na modalidade hala ${ }^{19}$ e que o horizonte religioso islâmico tem um papel preponderante.

Nessa atividade, há uma profunda ligação de crenças e princípios religiosos com a dinâmica econômica do setor. Mercados mo-

\footnotetext{
18 Fragmentos de entrevistas diretas realizadas junto a um grupo de senegaleses situados em Passo Fundo em sua residência, em 14 de setembro de 2016. Um dos entrevistados atua no setor de abate halal de um frigorífico em Passo Fundo. Porém, grande parte dos que residem na casa trabalhava, no período, como vendedores ambulantes em Passo Fundo e em cidades vizinhas.

19 O sistema de abate halal é uma prática que demanda exigências específicas no interior dos frigoríficos em que o frango deve estar totalmente vivo para abatê-lo, a sangria deve ser manual, não se pode decepar o frango e, sim, degolá-lo. Somente muçulmanos podem atuar no setor; há controles e vigilâncias rígidas nesse sentido. Frigoríficos da região de Passo Fundo otimizam esses processos efetivando contratos milionários com países muçulmanos e, com isso, fazem investimentos para alterar o sistema tradicional de abate. A presença de imigrantes favoreceu esse processo.
} 
dernos, altamente concorrentes e globalizados carregam dimensões simbólicas no campo das crenças e princípios religiosos históricos do Islã. Desse modo, fatores da tradição religiosa são otimizados pela dinâmica moderna do mercado globalizado do campo da alimentação; com isso, modernidade e tradição não são contrapostos e, sim, dinâmicas que se retroalimentam. Mundos religiosos se encontram e se cruzam em razão de premências das relações mercantis. Na realidade, a religião migra junto com os sujeitos e as instituições e o universo do trabalho lhe dá materialidade (Romero, 2017). Essa faz parte da cultura migratória e se alimenta por processos transnacionais para poder vincular os imigrantes em seu interior.

A possibilidade de expressar as crenças e/ou produzi-las no interior do cenário migratório em dimensões coletivas reforça a coesão, a identidade de grupos e demonstra o seu reconhecimento social. Isso tudo pode ser maximizado na esfera empresarial. Os trabalhos na certificação Halal são reveladores dessa realidade. Nesse sentido, ser imigrante e muçulmano torna-se um recurso, uma espécie de capital social a serviço do capital econômico, no caso empresarial, que atua no interior dos frigoríficos (Tedesco, 2017).

Fig. 1 - Senegaleses trabalhando no setor de abate halal em frigorífico. Chamamos atenção para a placa em frente, sobre a cabeça dos trabalhadores, em que há duas frases em árabe e a tradução em português diz: "Em nome de Deus. Deus é maior". Fonte: Pesquisa de campo em Passo Fundo, em novembro de 2016.

Essa relação de cunho religioso na esfera do trabalho significa dizer que há uma diluição e porosidade do primeiro no mercado econômico. Por isso, insistimos na ideia da manutenção de uma ordem simbólica/religiosa que conduz uma ordem social (Bourdieu, 1999) compreendida e atualizada pelos rituais, possuindo, além do efeito agregador e de identificação grupal, a consagração dos fiéis, ou seja, tudo feito em nome de Deus e de sua glória (Romero, 2017).

Os imigrantes, em geral, invocam a fidelidade às tradições de seu espaço de origem. Em razão da emigração dos homens ser maior do que das mulheres (emigram mais homens casados) (Daguerre, 2010), há uma grande ausência dos pais na educação dos filhos (mui- 
tos filhos viverão muito tempo sem a presença física dos pais), processo esse que delega, em grande parte às mães que permanecem e/ou aos avós, o cuidado dos filhos, ainda que se deva entender a importância da família ampliada (parentesco, compadrio e toda a estrutura normativa poligâmica) e a dimensão da socialização religiosa. Os imigrantes também necessitam lançar mão de coletividades para auxiliar no processo de educação e criação de filhos.

\section{“Estamos nos abrasileirando": integração e novas sociabilidades}

Já vimos que há uma idealização da emigração, como fonte de riqueza para a família e para a nação. "Se deves ajudar alguém, comece pela sua casa” (Friedberger, 2013, p. 8). Há no Senegal uma educação para a solidariedade (dividir custos nas casas, alcançar um prato de comida, receber quem necessita em sua casa, etc.). Essa "vida de grupo" (Mbodji, 2008) permite manter tradições (língua, solidariedade, divisão de custos, etc.), ser julgado por pares, ritualizar códigos morais, "não deixar nenhum imigrante sem guarida ainda que com muito custo. [...]. É nosso costume viver todos juntos, cheio de gente; [...], os amigos os hospedam [...], jantar em comum"20; isso é hábito no país, símbolo de unidade e de fraternidade (Moreno Maestro, 2006); é uma sociedade de "mutuo socorro" para garantir o enfrentamento dos riscos graves da emigração. "Mesmo não tendo amigos ou conhecidos, sabem que podem contar quando em algum lugar há senegalês". Consideram o individualismo negativo; a sua força está no coletivo, na organização solidária. Essa última, possui um caráter informal. Os mais velhos sentem-se na obrigação e responsabilidade em relação aos mais jovens e recém-chegados. É expressão do papel do idoso na sociedade senegalesa. É no grupo e pelo grupo que o senegalês busca o sucesso pessoal. A solidariedade se manifesta em sua forma mais intensa em momentos emergenciais, porém, faz parte do estilo de vida, de raízes culturais e históricas profundas ((Mbodji, 2008).

As dificuldades experimentadas pelos imigrantes também se expressam no campo subjetivo; a necessidade de manter contato com

20 Entrevistas diretas realizadas junto a um grupo de senegaleses situados em Passo Fundo em sua residência, em 14 de setembro de 2016. 
a família liga-se a um sentimento de solidão e distanciamento. Somam-se a esses sentimentos e obrigações morais e religiosas os problemas relacionados à apropriação da cultura ocidental brasileira, considerada excessivamente liberal, com conceitos e costumes que ameaçam o regimento de moralidade que baseia a leitura de mundo dos senegaleses e o dever de reproduzi-lo nos espaços de destino (Kleidermacher, 2015). É nesse momento que o âmbito religioso age como um respaldo às dificuldades enfrentadas, conferindo sentido a dilemas e carências pessoais experimentadas. Ao fazer as orações diárias, leitura do Alcorão, seguir os preceitos de conduta e orientação de vida, como não fumar, não beber, não trair a mulher e/ou marido, cuidar a alimentação, praticar os rituais - o Ramadã e as festividades religiosas específicas das confrarias, constituem-se em ações importantes, que tornam os processos religiosos, nas palavras de um dos entrevistados, formas de "se sentir em casa, tranquilo e andar no caminho reto". ${ }^{21}$

Na medida em que esses processos possibilitam representações e condutas tomadas especificamente pelo seu significado religioso, a imigração torna-se também um espaço religioso e, de forma específica e territorial, os imigrantes organizam-se para ter um local para expressar no grupo e em público esses rituais e significados simbólicos em suas vidas.

Fig. 2 e 3 - Festas regiliosas denominadas Grand Magal do grupo Mouride, na cidade de Passo Fundo, nos dias 1\%12/2016 e 8/11/2017. Fonte: Pesquisa de campo.

Nesse horizonte das tradições e das obrigações, e que se alimentam e ritualizam pelo ato do trabalho, está a família. Essa é um pilar do fenômeno emigratório; ela torna-se transnacional, com ligações flexíveis, estratégias, de dispersão para aproveitar oportunidades que os espaços de destino propiciam. O telefone territorializa as ligações no espaço de destino e liga as famílias de uma parte a outra das fronteiras (Simon, 2008). Há uma redistribuição do papel de chefe de família entre pais e filhos; pais em países diferentes e filhos no lugar paterno (Barau, 2007).

O território afetivo muda, ou seja, há uma movimento com-

21 Entrevista direta realizada com um participante da festa do Grand Magal de 2017. 
plexo entre lugares e pessoas (Simon, 2008). No universo da família, emerge a figura do "père humilié" (Diop, 2001), ou seja, a carência econômica da família reduz a autoridade do pai no interior dessa. A emigração passa a ser uma saída para a reconfiguração dos papéis, esses serão reincorporados pela dinâmica do dinheiro e não tanto pelas relações de copresença cotidiana.

$\mathrm{Na}$ decisão de emigrar, entrevistados enfatizam a importância da benção dos líderes religiosos, denominados de Serignes ou Marabuts; "junto com eles, a gente reza pedindo proteção; confiança em Deus [...], se tem confiança, entrega na mão de Deus, e não tem medo, enfrenta todo esse trajeto que te disse sem medo". Porém, não é só o trajeto que os desafia, mas, também, as mudanças culturais, os valores e costumes de uma sociedade diferente, seus regramentos, o "fato de proibir vender coisas na rua, que para nós é tudo normal no Senegal"; "aqui eu tenho meda das mulheres, por isso, não quero namorar aqui, elas saem quando querem, decidem ir pra cá e pra lá [...]; lá no Senegal não é assim". ${ }^{22}$

Os processos integrativos e/ou assimilacionistas são normais e comuns com o passar do tempo no cenário migratório. Imigrantes se inserem em múltiplos processos sociais e culturais em que se esforçam para demarcar fronteiras identitárias. Imigrantes revelam a falta de conhecimento de brasileiros sobre eles e o Senegal. "Acham que não temos nada, só doença e selva na África. [...]. Já que eles não sabem de nós, também nós pouco ou nada sabemos daqui e também não interessamos. [...]. A língua sim, essa a gente tem de saber".

Numa narrativa que obtivemos com um representante religioso na cidade de Passo Fundo, a preocupação com as mudanças socioculturais é muito grande. Diz ele entender ser normal isso, porém, "não podem perder aquilo que é central deles que é a vida religiosa, a solidariedade, o caminho reto." ${ }^{23}$ Há casamentos mistos, participação de senegaleses em horizontes sociais e de lazer na sociedade autóctone, presença em univer-

22 Entrevistas diretas realizadas junto a um grupo de senegaleses situados em Passo Fundo em sua residência, em 14 de setembro de 2016. A maioria deles trabalha como vendedores ambulantes em Passo Fundo e em cidades vizinhas.

23 Entrevista direta com representante da associação muçulmana de Passo Fundo. O interlocutor habita em Passo Fundo há cinco anos; além do campo religioso, ele auxilia na orientação documental e de espaços de trabalho para os imigrantes muçulmanos, em particular, senegaleses, bengalis, ganeses e eritreus. 
sidades, em escolas de ensino médio, em cursos profissionalizantes; alguns se tornam empresários e empregam co-nacionais. Em seus espaços de habitação, as programações televisivas, as músicas e outras manifestações "do jeito brasileiro [...], vai abrasileirando eles, mas eles também começam a questionar tal e tal coisa do povo daqui, fazem as comparações; alguns aderem, outros reforçam o que foram no Senegal". ${ }^{24}$

Em entrevistas, senegaleses dizem que eles têm "medo da mulher brasileira", que ela é muito independente e quer sair a toda a hora, além de ir em festas, se divertir". Informam que eles "são diferentes", que a mulher no Senegal "não é assim, é o homem que determina". Ao mesmo tempo em que expressam esse modo de ver, há vários casamentos mistos, há presença de senegaleses em espaços de lazer (boates, clubes, CTGs, dentre outros espaços públicos de lazer). Vários entrevistados informaram que há um intenso desejo de integração social; um deles diz que já se sente "meio brasileiro e meio senegalês", mas ressalva que, para eles, não é bom ser mais do que a metade, pois "o jeito de vocês é bom, mas praticam pouco a religião, querem se divertir só”. Há horizontes ambíguos, complexos e que fazem parte da cultura de contato, de processos integrativos, da vida de imigrante, a qual se revela com limites e numa situação de temporário, pois, todos os entrevistados manifestaram desejo de um dia retornar ao seu país.

Imigrantes são, por essência, sujeitos portadores de identidades múltiplas, em boa parte, transversais e, por isso, alimentam sempre diferenças culturais (Ambrosini, 2010). Essas diferenças acabam por criar identificações estratégicas de pertencimento, lógicas identitárias que evocam diferenciações das alteridades para servir de referências e/ou de espelhos, de contrapontos, quando não para desqualificar e/ou estigmatizar. Nesse sentido, produz-se um jogo em que a etnicidade serve para provocar alianças, mas, também, rupturas e recomposições, negociações, patrimônios tornados comuns (Boubeker, 2003) ou diferenciados pela situação de contato, demonstrando como os fatores considerados culturais e de identificação histórica de algum grupo são dinâmicos (Zanini, 2006).

24 Entrevista direta com representante da associação muçulmana de Passo Fundo. O interlocutor habita em Passo Fundo há cinco anos; além do campo religioso, ele auxilia na orientação documental e de espaços de trabalho para os imigrantes muçulmanos, em particular, senegaleses, bengalis, ganeses e eritreus. 
As identidades culturais têm muito a ver com as estratégias adotadas pelos indivíduos em suas interações, nessas, os atores/ grupos sociais se distinguem, fazem ver seu pertencimento étnico (Kleidermacher, 2013). Nacionalidades são reconhecidas também na forma de contrastes. A etnicidade, portanto, também, baseia-se nos contrastes e comparações, com isso, produz relações e convívios não tão harmônicos, em particular nos cenários em que elas se apresentam com intensidade, como o é nos territórios de imigração. Por isso que o processo identitário se constrói nas correlações e confrontos que definem fronteiras; é a experiência em relação ao outro que promove a consciência de um "eu" e de um "nós" (Bauman, 2017; Zanini, 2006). As identificações que são produzidas no interior das sociedades hospedeiras são (re) construídas pelos autóctones e estrangeiros também a partir desses referenciais simbólicos.

Enfim, imigrantes senegaleses demonstram estar muito conectados em espaços sociais diversos, de uma parte, pela sua presença e identidade étnico-cultural no país de origem, de outra, pelos vínculos e mediações junto ao país que os hospeda; ou, então, por relações mantidas e estabelecidas à distância com a família e amigos no local de origem. Isso permite alimentar relações sociais nos contextos de proveniência, contribuir para modelar projetos, representações, pertencimentos, circulação entre dois territórios, fazer negócios, acordos etc., encurtando distâncias, diferenciando as conseqüências das fronteiras de até então. Isso tudo permite reproduzir formas de pertencimento, "comunidades de sentimento", de crença religiosa, interagindo valores, desenvolvendo representações em torno do Brasil, ressignificando a vida do imigrante e permitindo seus translados virtuais, emotivos e afetivos.

\section{Considerações finais}

Imigrantes senegaleses marcam presença na sociedade do centro-norte do Rio Grande do Sul. Vimos que é uma imigração recente, mas que chama muito a atenção da população por vários motivos. Motivos variados também os conduziram até ela. No seu inte- 
rior, eles buscam encontrar espaços, lançam mão de estratégias para fazer valer seu difícil e complexo caminho para chegar no destino.

O projeto emigratório é totalmente orientado para o sustento dos que ficaram, a estrutura do espaço religioso torna possível fazer parte da vida social e também religiosa em seu país. Outro ponto bastante importante relacionado ao distanciamento é a perspectiva de paternidade e/ou genitorialidade à distância. Nesse sentido, a estrutura social da confraria já auxilia na constituição de um prestígio e autoridade conferida ao indivíduo que garante o sustento; isso auxilia na representação do pai e/ou da mãe (emigrantes) junto aos filhos. É nesse ponto que também se apresenta a importância das estruturas de comunicação fornecidas pelas atuais tecnologias móveis, que barateiam o custo de manter o contato com a sociedade de origem.

Senegaleses são imigrantes laborais; os espaços de trabalho são variados; percebe-se uma grande inserção em espaços agroindustriais (de aves e bovinos), alguns com especificidades por serem adeptos ao horizonte religioso islâmico. Nesse sentido, vimos que há identidades sociais em jogo, papéis sociais de homem/mulher, marido/ esposa, pai/mãe, pertencimentos religiosos transnacionalizados e em redes que viabilizam vínculos e processos de solidariedade no interior do grupo e uma expressão de adequação aos princípios de fé em ação.

As obrigações morais (solidariedade, comunidade, entreajuda, reciprocidade, dentre outras) passam a ser fundamentais do sustento moral, psicológico e econômico dos imigrantes. O campo religioso transforma-se numa totalidade de vida para os senegaleses, produz hierarquias religiosas, lideranças, rituais cotidianos e públicos, festejos, locais de cultos e a mística necessária para o viver cotidiano e enfrentar as adversidades e limites da situação de imigrante.

Todos enviam o máximo que podem dos recursos financeiros obtidos do seu trabalho ao Senegal, em particular, às famílias. Os imigrantes estruturam-se em torno de lideranças e de esferas associativas (de nacionalidade e de pertencimento religioso); organizamse e desenvolvem rituais coletivas de expressão religiosa, fato que revela processos integrativos e de maturação da identidade de imigrante na sociedade regional. 
Em termos identitários, fluidez e estabilidade são dinâmicas em ação; uma não pode ser absolutizada em detrimento da outra. Esse processo revela um horizonte amplo de relações e contatos, mas, também, certa fragilidade de "dupla" integração ao fazer parte de duas sociedades diferentes. As interações sociais específicas que o processo migratório apresenta refletem as idealizações do retorno e da permanência, as lembranças e os desejos do vivido e concebido em tempos anteriores, bem como faz refletir e reavaliar pertencimentos (Zanini, 2006). Exclusão e inclusão num espaço ou no outro, são dinâmicas que obedecem a horizontes que se fundam nas condições, relações e concepções que os sujeitos envolvidos produzem em seu cotidiano (de trabalho, de convivência grupal e de expressão religiosa) e nas projeções e aquisições efetivadas no local de origem. Por isso, o retorno ao local de origem é muito importante. Nos relatos que obtivemos de uma forma aprofundada, essa questão do retorno demonstrou ser fundamental.

Vimos que imigrantes e representantes religiosos enfatizam o temor do "abrasileirar-se", de perder referenciais que lhes são significativos para manter vínculos, promessas e obrigações com o espaço de origem. Há vários casamentos mistos, outros arranjados para obter a cidadania brasileira e permitir o reagrupamento familiar de origem ${ }^{25}$. Nesse sentido, a imigração exacerba e complexifica os quadros jurídicos, sociais e políticos inerentes à transmissão de valores e de formas culturais; revela também capacidade de negociar com os dois horizontes espaciais e culturais.

Enfim, buscamos, de uma forma sintética, fazer um esforço para apreender conflitos, tensões, temores, enfretamentos e estratégias que fazem parte do cenário de uma migração recente no norte do Rio Grande do Sul. Talvez isso que vimos não seja muito diferente com outros grupos étnicos e nem em outros espaços e situações no país, porém, revela uma dinâmica em construção, processos em adaptação e movimento, sujeitos sociais em ação e que nos propiciam entender realidades

25 Esse tema dos casamentos mistos e suas várias estratégias está sendo objeto de pesquisa, porém, até o momento, conseguimos levantar dados estatísticos e alguns horizontes relacionais. $\mathrm{O}$ que nos chama a atenção é que há, na cidade de Passo Fundo, mulheres, profissionais do sexo (prostitutas) que estão sendo envolvidas nesse arranjo estratégico para viabilizar a cidadania brasileira a senegaleses. 
que se produzem em cenários da imigração contemporânea.

\section{REFERÊNCIAS}

AMBROSINI, M. Italiani con trattino: identità e integrazione tra i figli degli immigrati. Lecce: Edizioni Grifo, 2010.

AMBROSINI, M. Un'altra globalizzazione. La sfida delle migrazioni transnazionali. Bologna: Il Mulino, 2008.

BARAU, J. La planète des migrants. Circulations migratoires et constituition de diásporas à l'aube du XXI siècle. Paris: Armando Colin, 2007.

BARAU, J. Les immigrés d'Afrique subsahariénne en Europe. Une nouvelle diaspora? In: Revue Européenne des Migrations Internationales. Rennes, (28), p. 147-167, 2012.

BAUMAN, Z. Dentro la globalizzazione. Le conseguenze sulle persone. Roma-Bari: Laterza, 1999.

BAUMAN, Z. Estranhos à nossa porta. Rio de Janeiro: Zahar, 2017.

BAUMAN, Z. Voglia di comunità. Roma: Laterza, 2001.

BOUBEKER, A. Les mondes de l'éthnicité. Voix et regardes. Paris: Ballaud, 2003.

BOURDIEU, P. A economia das trocas simbólicas. São Paulo: Perspectiva, 1999.

CEPED (Centre du Études sur la Population et Developpement). West African from explosion to proliferation. 2017. Document.

DAGUERRE, V. L'immigrations: problématiques et défis. Paris: Éditions du Cygne, 2010.

DIAL, F. B.; SAKHO, P. Migration clandestine féminine: etude de cas de Dakar et sa banlieu. Notes d'analyse et de Synthèse, Dakar: UCAD, n. 56, 2014.

DIOP, M. C. (Éd). La société sénégalaise entre le local et le global. Paris: Kathala, 2002.

DIOP, M. C. Mobilités, Ètat et société. In: (Dir.). Le Sénégal des migrations. Mobilités, identités, et sociétés. Paris: Karthala, 2001, p. 13-34.

FALL, P. D. Migration, marché du travail et développement. Dakar: UCAD, 2010.

FRIEDBERG, O. S. Islam, solidarietà e lavoro. I Muride senegalesi in Italia. Milano: Fondazione Agnelli, 2013. 
GAMBERONI, E.; PISTOCCHI, F. L'Africa occidentale. Ritratto di un'Africa che cambia. Bologna: Pàtron Editore, 2013.

HERÉDIA, V. B. M.; TEDESCO, J. C. O lugar do imigrante nos espaços de trabalho em Caxias do Sul: o caso dos senegaleses. In: HEREDIA, V. B. M. (Org.). Migrações internacionais: o caso dos senegaleses no Sul do Brasil. Caxias do Sul: Quatrilho Editorial, 2015, p. 137170.

KAAG, M. Il ruolo dela confraternita dei Muiridi nella vita dei migrante senegalesi. In: PALTRINIERI, A. C. (a cura di). Un futuro in gioco. Tra muridi senegalesi e comunità italiana. Milano: Franco Angeli, 2006, p. 125-131.

KLEIDERMACHER, G. Entre confrarias y venta ambulante: una caracterización de la inmigración senegalesa em Buenos Aires. Cuadernos de Antropología Social, Buenos Aires: UBA, n. 38, p. 109-130, 2013.

KLEIDERMACHER, G. Movilidad e insercíon de inmigrantes senegaleses recientes en la Ciudad Autónoma de Buenos Aires. Revista Internacional de Estudios Migratorios (RIEM), v. 5, n. 1, p. 93-118, 2015.

MALOMANO, B.; FONSECA, D. J.; BADI, M. K. Diáspora africana e migração na era da globalização: experiências de refúgio, estudo, trabalho. Curitiba: CRV, 2015.

MBODJI, M. Imaginaires et migrations. In: DIOP. M. C. (dir.). Le Sénégal des migrations: mobilité, identités et sociétés. Paris: Karthala, 2008, p. 303-318.

MORENO MAESTRO, S. Aqui y allí, viviendo en los dos lados. Los senegaleses de Seviela. Una comunidad transnacional. Siviela. Junta de Andalucía, 2006.

NDIONE, B. (Ed.). Les Statistiques des travailleurs migrants en Afrique de l'Ouest: Synthèse sous-regionale. Projet: Migration de maind'oeuvre pour l'integration et le developpement en Afrique. Dakar: ILO, 2016.

ROGOFF, Barbara. Transformações culturais e relações entre comunidades. In. A natureza cultural do desenvolvimento humano. Porto Alegre: Artmed, 2005, p. 265-294.

ROMERO, F. L. Islã, parentesco e ritual na irmandade religiosa Mouridiyya: percursos da etnografia no contexto da imigração de africanos senegaleses no Brasil. In: TEDESCO, J. C.; KLEIDERMACHER, G. (Org.). A imigração senegalesa no Brasil e na Argentina: múltiplos olhares. Porto Alegre: EST Edições, 2017, p. 275-296.

SAKHO, P.; DIOP, R. A.; AWISSI-SALL, M. Migration et genre au Sénégal. Florence: European University Institute, 2011. 
SASSEN, S. Una sociologia della globalizzazione. Torino: Einaudi, 2008.

SAYAD, A. A imigração ou os paradoxos da alteridade. São Paulo: Edusp, 2008.

SEYFERTH, G. et al. Mundos em movimento. Ensaios sobre migrações. Santa Maria: Editora da UFSM, 2007.

SHAKO, P.; DIOP, R. A.; MBOUP, B.; DIADIOU, D. A emigração internacional senegalesa: das casas no campo às cidades litorâneas. In: HEREDIA, V. B. M. (Org.). Migrações internacionais: o caso dos senegaleses no sul do Brasil. Caxias do Sul: Quatrilho Editorial, 2015, p. 23-50.

SIMON, G. La planète migratoire dans la mondialisation. Paris: Armand Colin, 2008.

TEDESCO, J. C. “Em nome de...”: religião, trabalho e mercado. Senegaleses em frigoríficos do centro-norte do Rio Grande do Sul. In: TEDESCO, J. C.; KLEIDERMACHER, G. A imigração senegalesa no Brasil e na Argentina: múltiplos olhares. Porto Alegre: EST Edições, 2017, p. 311-338.

THIAM, M. T.; CROWLEY, J. Impact des changements environnementaux sur les migrations humane. Études de cas: Sénégal et Côte d'Ivoire. Unesco: Jerin, 2014.

UEBEL, R. Análise do perfil socio-espacial das migrações internacionais para o Rio Grande do Sul no início do século XXI. Encarte da Revista Semana da África. UFRGS/NEAB, 2016.

WIHTOL DE WENDEN, C. Atlas des migrations dans le monde. Paris: Altrement, 2005.

WIHTOL DE WENDEN, C. La question migratoire au XXIe siècle. Paris: Presses de Sciences Po, 2013.

ZANINI, M. C. Italianidade no Brasil Meridional: a construção da identidade étnica na região de Santa Maria - RS. Santa Maria: UFSM, 2006. 